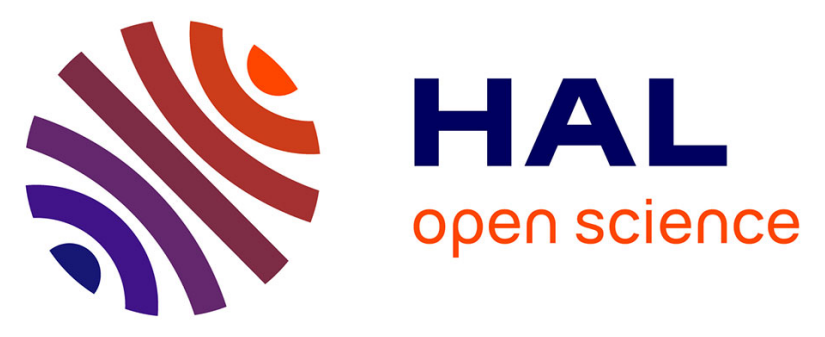

\title{
Influence of process parameters on thermal and mechanical properties of polylactic acid fabricated by fused filament fabrication
}

Hamidreza Vanaei, Mohammadali Shirinbayan, Michael Deligant, Kaddour Raissi, Joseph Fitoussi, Sofiane Khelladi, Abbas Tcharkhtchi

\section{To cite this version:}

Hamidreza Vanaei, Mohammadali Shirinbayan, Michael Deligant, Kaddour Raissi, Joseph Fitoussi, et al.. Influence of process parameters on thermal and mechanical properties of polylactic acid fabricated by fused filament fabrication. Polymer Engineering and Science, 2020, 60 (8), pp.1822-1831. 10.1002/pen.25419 . hal-02943964

\section{HAL Id: hal-02943964 \\ https://hal.science/hal-02943964}

Submitted on 21 Sep 2020

HAL is a multi-disciplinary open access archive for the deposit and dissemination of scientific research documents, whether they are published or not. The documents may come from teaching and research institutions in France or abroad, or from public or private research centers.
L'archive ouverte pluridisciplinaire HAL, est destinée au dépôt et à la diffusion de documents scientifiques de niveau recherche, publiés ou non, émanant des établissements d'enseignement et de recherche français ou étrangers, des laboratoires publics ou privés. 


\section{Influence of process parameters on thermal and mechanical properties of polylactic acid fabricated by fused filament fabrication}

\author{
Hamidreza Vanaei $^{1,2}$ (i) | Mohammadali Shirinbayan ${ }^{2}$ | Michael Deligant $^{1}$ | \\ Kaddour Raissi $^{1}$ | Joseph Fitoussi ${ }^{2}$ | Sofiane Khelladi ${ }^{1}$ | Abbas Tcharkhtchi ${ }^{2}$
}

${ }^{1}$ Arts et Metiers Institute of Technology, CNAM, LIFSE, HESAM University, Paris, France

${ }^{2}$ Arts et Metiers Institute of Technology, CNRS, CNAM, PIMM, HESAM

University, Paris, France

\section{Correspondence}

Hamidreza Vanaei, Arts et Metiers Institute of Technology, CNAM, LIFSE, HESAM University, 75013 Paris, France. Email: hamidreza.vanaei@ensam.eu

\begin{abstract}
Fused filament fabrication is considered one of the most used processes in additive manufacturing rapid prototypes out of polymeric material. Poor strength of the deposited layers is still one of the main critical problems in this process, which affects the mechanical properties of the final parts. To improve the mechanical strength, investigation into various process parameters must be considered. In this article, the influence of different process parameters has been experimentally investigated by means of physicochemical and mechanical characterizations. Special attention was given to the thermal aspect. In that respect, the in situ measurement of temperature profile during deposition indicated that several parameters affect the cooling rate of material and consequently have an influence on the final parts. It was found that the influence of increasing the extruder temperature is more significant in comparison with other process parameters.
\end{abstract}

KEYWOR D S

$\mathrm{FFF}$, in situ temperature measurement, polylactic acid, process parameters

\section{1 | INTRODUCTION}

Fused filament fabrication (FFF) is one of the numerous additive manufacturing (AM) processes. In FFF, a threedimensional (3D) geometry is formed through the deposition of successive layers of extruded thermoplastic filament (eg, polylactic acid [PLA], acrylonitrile butadiene styrene [ABS], polypropylene [PP], polyethylene [PE], Nylon, or polyether ether ketone $\left.[\mathrm{PEEK}]^{[1]}\right)$. In this process, the filaments are extruded in layers parallel to the $\mathrm{X}-\mathrm{Y}$ plane and that the layers are built in a successive manner in the Z-direction to create a layer-by-layer 3D part. ${ }^{[2]}$ Due to the generated heat by extruder, the hot layer deposited onto the previous one. The previous layer is in the progress of cooling and causes cooling and reheating of substrate layers. ${ }^{[3,4]}$ It is thought that the bonding of two adjacent filaments would be directly affected by this temperature profile because of the cyclic temperature profile of the polymer during deposition.

The abilities to fabricate complex geometries and lower cost of manufacturing have made research studies motivated into various characterizations and improvements of parts fabricated by FFF. ${ }^{[5-7]}$ Despite the mentioned advantages, mechanical properties of parts manufactured by FFF process are inherently poor, ${ }^{[8]}$ which is why it is required to consider the mechanical properties of 3D-printed materials compared with the conventional methods. ${ }^{[9]}$

In order to have a better understanding of the features of temperature profile between adjacent filaments, 
various mathematical approaches have been proposed. A transient heat transfer has been proposed to analyze the filament deposition with physical contacts between any filament and its neighbors. ${ }^{[10]}$ Also, a twodimensional heat transfer model of two filaments was generated to consider the temperature evolution during FFF process using the finite element method. ${ }^{[11]}$ Furthermore, a one-dimensional transient heat transfer model was developed by Sun et $\mathrm{al}^{[12]}$ and combined with the spherical particle sintering model. ${ }^{[13]}$ They estimated the FFF temperature profile and the bond formation for a single filament depositing process.

In FFF process, each parameter has its own influence on the microstructure and filaments bonding of the fabricated parts. ${ }^{[8,14,15]}$ There are three important groups of influencing parameters:

1. Material parameters, such as molecular weight, density, surface tension, thermal conductivity, heat capacity, moisture in polymer, melting temperature, crystallization temperature, and glass transition temperature.

2. Process parameters, such as nozzle temperature, chamber temperature, road width, speed print head, layer thickness, air pocket, and frame angle.

3. Machine parameters, such as nozzle shape, nozzle temperature, print head, positioning accuracy $x-y$, and positioning accuracy y-z.

Many studies also focused on finding a relationship between the mechanical properties and processing parameters of FFF process in printed parts, such as layer thickness or frame angle. ${ }^{[16]}$

In this article, an overview of the process parameters is presented. The experimental procedure is explained. Then, different experimental characterization results are presented. Finally, the temperature evolution of PLA filaments during FFF process was performed as a function of different parameters. The aim of these case studies is to study the effect of each parameter on the mechanical and thermal behavior of fabricated parts. This research is useful for designing and optimizing the process parameters by improving the mechanical properties of products manufactured by FFF.

\section{2 | AN OVERVIEW ON THE PROCESS PARAMETERS IN FFF}

Due to the nature of FFF, almost all the 3D-printing machines comprise various process parameters. The temperature of nozzle and chamber, path width, print speed, layer thickness, air pocket, and frame angle could be considered in the characterization of fabricated parts. Almost all of them affect the filament bonding and consequently the mechanical behavior of 3D-printed parts. However, researchers tried to focus on some key parameters to optimize the experimental procedure and finally get the combination of parameters. ${ }^{[1]}$ Various research studies considered the influence of process parameters on the parts fabricated using FFF. Build orientation and frame angle and their effect on the mechanical properties of 3D-printed parts have been consequently studied, and the effect of raster angle by consideration of infill patterns has been analyzed. ${ }^{[8,16]}$

In addition, another research reported the effect of inprocess and postprocess on thermal global state during parts 3D printing and highlighted the importance of environment and support temperatures. ${ }^{[18]}$ Diffusion and neck growth between two adjacent filaments would be affected by changing of environment or support temperatures, which confirms the importance of heat transfer in this process.

Regarding the applied material and studied parameters, it was found that almost all researchers tried to consider the effect of parameters by different methods of characterization (eg, tensile or bending) with using a unique parameter at different values. A brief representation of research studies on various materials is given in Table 1 .

Almost all these studies are based on the consideration of improving the mechanical behavior of materials. Consequently, it is not possible to have a comparison between all the process parameters due to the different material and manufacturing conditions or type of the machine.

Although Ahn et $\mathrm{al}^{[24]}$ studied the effect of layer thickness (height) on ABS specimen, they concluded that mechanical behavior of the material is not affected by the variation of this parameter. Sood et $\mathrm{al}^{[28]}$ showed that the smallest value of layer thickness contributes to better tensile behavior. Besides, other research studies showed that as much as the layer height decreased, mechanical behavior improved. ${ }^{[25,29]}$ Furthermore, based on the mentioned studies on the effect of process parameters, it was extracted that there are not sufficient research studies on the effect of temperature (namely liquefier, support, and environment temperature) and print speed (that could act as a factor in cooling of the material) on the fabricated parts. Rodríguez et $\mathrm{al}^{[30]}$ concluded that there is no influence of support temperature on the mechanical behavior of the fabricated parts as well as the study performed by Ahn et al. ${ }^{[24]}$ However, Sun et $\mathrm{al}^{[3]}$ and Xiaoyong et $\mathrm{al}^{[27]}$ showed that the support temperature affects the mechanical behavior of the printed parts.

Eventually, from the above description of the previous research studies and also the fact that each of them considered a portion parameters' values, it would be useful to be noted that the interaction of parameters plays 
T A B L E 1 Representation of FFF-based research studies in consideration of process parameters

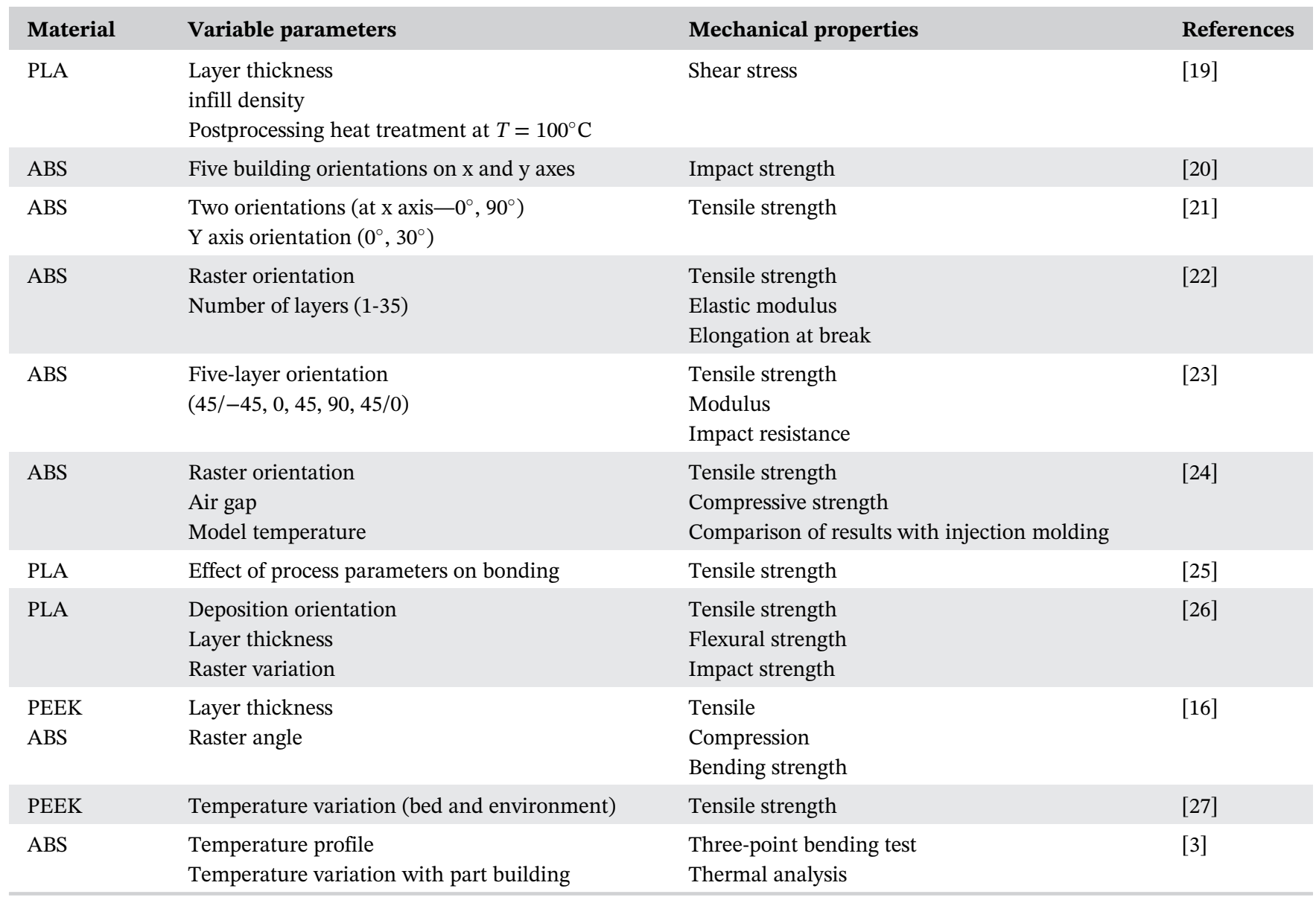

Abbreviations: FFF, fused filament fabrication; PLA, polylactic acid; ABS, Acrylonitrile butadiene styrene; PP, Polypropylene; PE, Polyethylene; PEEK, Polyether ether ketone.

the most important role in consideration of mechanical characterization of the fabricated parts. Due to these observations, the effect of a group of process parameters has been studied in the following 3D-printing experimental study.

\section{3 | MATERIALS AND METHODS}

\section{1 | Material, 3D printer, and sample preparation}

A commercially PLA filament with a diameter of $1.75 \mathrm{~mm}$ and the density of $\rho=1.24 \mathrm{~g} / \mathrm{cm}^{3}$ has been used. As shown in Figure 1, a unidirectional moving of the extruder assumed to deposit the filaments once against each other's having a more homogenous shape for temperature measurements. A desktop 3D printer was then used by fixing the temperature of liquefier and support to produce the pieces. One can note that three samples per parameter set were used. The sampling position for all characterizations is shown in Figure 1.

\section{2 | Process parameters classification}

As mentioned, there are various parameters in 3D printing that affect the mechanical behavior of filaments and the strength of the fabricated parts. Then, it is important to classify these parameters to have a comparison between them (Table 2).

\section{3 | Characterization methods}

\subsection{1 | Physicochemical characterization}

Differential scanning calorimetry (DSC) was performed using a TA Instruments Q1000. Samples ( $\sim \mathrm{mg}$ ) were sealed in aluminum pans and heated from room temperature to $200^{\circ} \mathrm{C}$ with a heating rate of $10^{\circ} \mathrm{C} / \mathrm{min}$ to determine the crystallization and melting temperature of the filaments. Then, the crystallinity of PLA was calculated using the following equation ${ }^{[31]}$ :

$$
X_{c}=\left(\Delta H_{m}-\Delta H_{c}\right) / \Delta H_{m}^{0},
$$



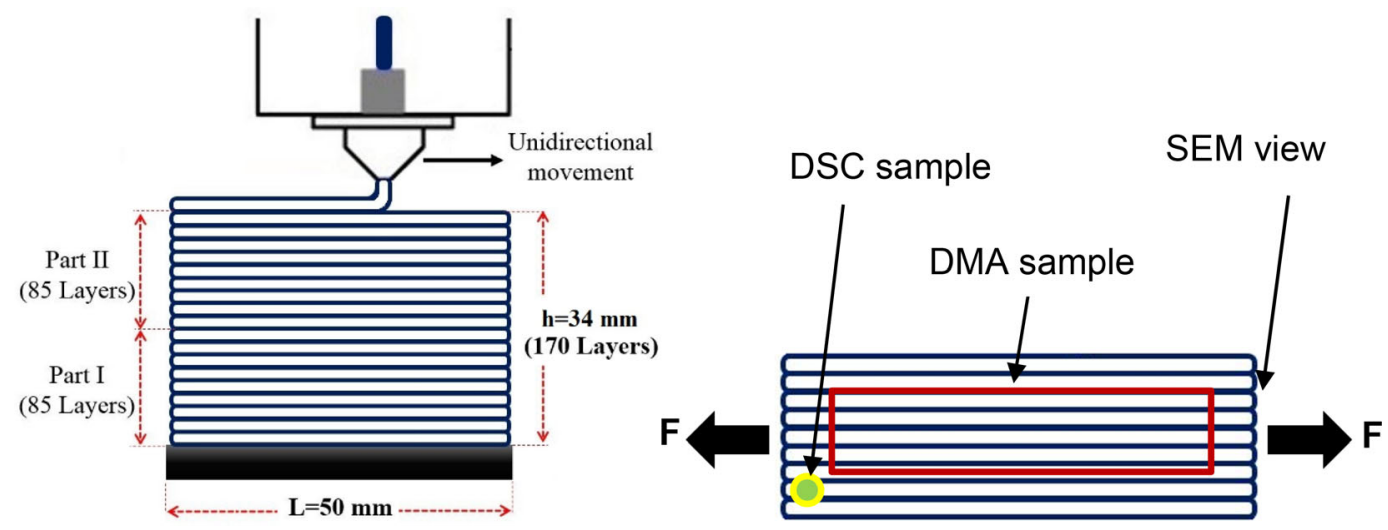

F I G U RE 1 Schematic of the test sample: dimension of the applied test sample and deposition mechanism of layers (thickness $=0.2 \mathrm{~mm}$ ) [Color figure can be viewed at wileyonlinelibrary.com]

T A B L E 2 Representation of the groups of process parameters

\begin{tabular}{|c|c|c|c|c|}
\hline Condition No. & Liquefier temperature $\left({ }^{\circ} \mathrm{C}\right)$ & Support temperature $\left({ }^{\circ} \mathrm{C}\right)$ & Speed $(\mathrm{mm} / \mathrm{s})$ & Layer height (mm) \\
\hline 1 & $\begin{array}{l}200 \\
210 \\
220 \\
230\end{array}$ & 50 & 20 & 0.2 \\
\hline 2 & 210 & $\begin{array}{r}50 \\
70 \\
100\end{array}$ & 20 & 0.2 \\
\hline 3 & 210 & 50 & $\begin{array}{l}20 \\
40 \\
60\end{array}$ & 0.2 \\
\hline 4 & 210 & 50 & 20 & $\begin{array}{l}0.1 \\
0.2 \\
0.3\end{array}$ \\
\hline
\end{tabular}

where $\Delta H_{c}$ and $\Delta H_{m}$ are the enthalpies of cold crystallization and melting, respectively. Also, the heat of melting $\left(\Delta H_{m}^{0}\right)$ of $100 \%$ crystalline PLA considered equal to $93.7 \mathrm{~J} / \mathrm{g}^{[31]}$ according to the literature.

Dynamic mechanical analysis (DMA) was used to measure the glass transition temperature. DMA tests have been performed on the samples using DMA Q800 Instrument from TA Company. The tests have been realized with a sample size of $25 \times 10 \times 4 \mathrm{~mm}^{3}$ under tensile mode at the following conditions: temperature range $40^{\circ} \mathrm{C}$ to $100^{\circ} \mathrm{C}$, frequency $1 \mathrm{~Hz}$, and temperature rate of $2^{\circ} \mathrm{C} / \mathrm{min}$.

\subsection{2 | Mechanical properties}

Tensile tests until failure have been carried out on INSTRON 4301 machine. The specimen geometry used for the quasi-static tensile test was based on a rectangular specimen. The dimension of the specimen defined to be $50 \times 17 \times 0.2 \mathrm{~mm}^{3}$. However, based on the dimensional change that occurs during the process, a digital caliper was used to precisely measure the required dimension. All calculations regarding mechanical behavior have been proposed as mentioned. The loading velocity was $1 \mathrm{~mm} / \mathrm{min}$.

\subsection{3 | Microstructure observation}

Microscopic observation, using a scanning electron microscope (SEM; HITACHI 4800 SEM), was performed to investigate the material microstructure and especially the deposition sequence of adjacent filaments. The ImageJ software was also used to evaluate the dimension variation using SEM micrographs.

\subsection{4 | Online temperature monitoring of filaments during deposition}

Due to multilayer deposition, there is a cyclic temperature profile in FFF process. This is a critical issue to the formation of them and consequently their strength. To 
measure this cyclic temperature, it is required to use a device that can measure the temperature of the polymer. A thermocouple type $K$ with a diameter of $80 \mu \mathrm{m}$, capable of measuring temperature from $-75^{\circ} \mathrm{C}$ to $250^{\circ} \mathrm{C}$ was used. ${ }^{[32]}$ To measure the temperature evolutions, a measurement device "Datapaq Tracker Telemetry system" was used (an in situ measurement device using in rotational molding process ${ }^{[33]}$ ).

\section{4 | EXPERIMENTAL RESULTS AND DISCUSSIONS}

\section{1 | Process parameters effects}

\subsection{1 | Influence of liquefier temperature}

The influence of liquefier temperature has been studied. Four values of liquefier temperature were chosen $\left(200^{\circ} \mathrm{C}\right.$, $210^{\circ} \mathrm{C}, 220^{\circ} \mathrm{C}$, and $230^{\circ} \mathrm{C}$ ). Based on Figure 2 and the data presented in Table 3, DSC results showed that for each value of liquefier temperature, there is a variation in the crystallization zone, which affects the crystallinity of the material during the process.

Figure 3 shows the tensile behavior at different values of liquefier temperature. Results showed that as much as

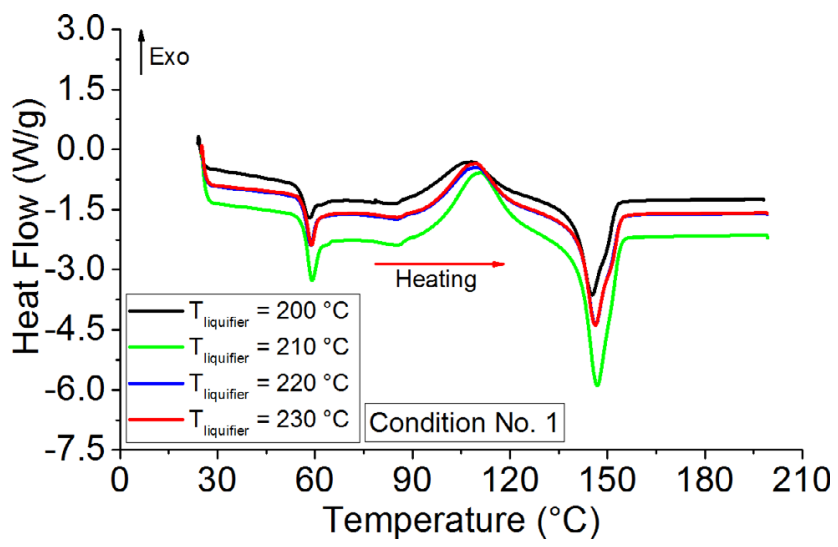

F I G U RE 2 Differential scanning calorimetry (DSC) results for samples fabricated at different liquefier temperatures [Color figure can be viewed at wileyonlinelibrary.com] the crystallinity increased, ultimate strength slightly increased. The highest crystallinity (in condition No. 1) refers to the liquefier temperature $T=220^{\circ} \mathrm{C}$. In fact, PLA is a polyester. In the family of polyesters, the crystallization can be slow or rapid. For PLA, the crystallization depends on the crystallization rate or speed. However, it is limited.

Moreover, at $T=200^{\circ} \mathrm{C}$, the value of Young's modulus is higher than others. One can note that the results show the same failure strain.

SEM micrographs on two samples under condition No. 1 are shown in Figures 4 and 5. In this regard, for the sample produced by a liquefier temperature of $T=200^{\circ} \mathrm{C}$ with the highest Young's modulus, one can note that the brittle failure of samples (Figure 4).

However, for the samples produced by the liquefier temperature of $T=220^{\circ} \mathrm{C}$, one can observe that the ductility increased as shown in Figure 5 in which the plastic deformation is observable in the sequence of SEM micrographs.

\subsection{2 | Influence of support temperature}

Based on the degree of crystallinity and the value of crystallization temperature (see Table 4): (a) the increase of support temperature to $T=70^{\circ} \mathrm{C}$ provides more

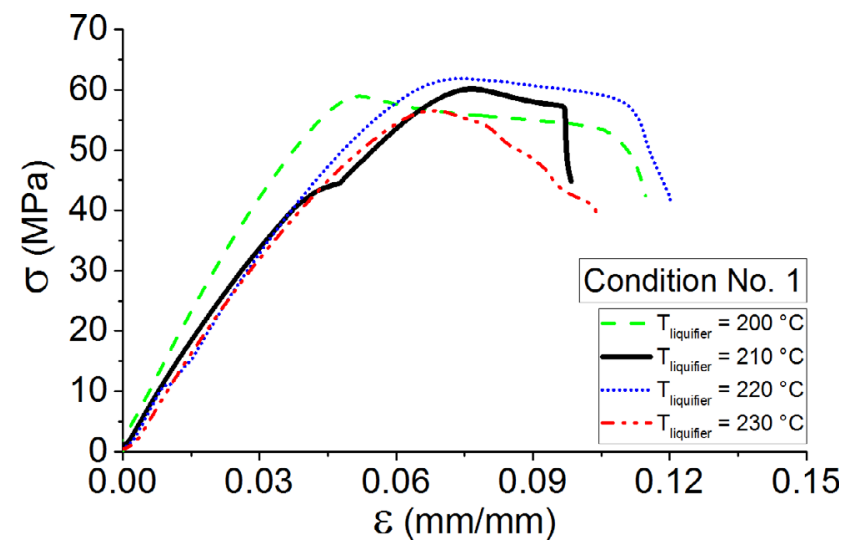

F I G U RE 3 Tensile behavior of condition No. 1 for various liquefier temperatures [Color figure can be viewed at wileyonlinelibrary.com]

T A B L E 3 Value of different properties obtained from DSC, DMA, and tensile results for condition No. 1

\begin{tabular}{|c|c|c|c|c|c|c|c|}
\hline \multicolumn{2}{|c|}{ Conditions } & $\begin{array}{l}\boldsymbol{T}_{\boldsymbol{g}}\left({ }^{\circ} \mathrm{C}\right) \\
62.3\end{array}$ & $\begin{array}{l}\boldsymbol{T}_{c}\left({ }^{\circ} \mathrm{C}\right) \\
108.4\end{array}$ & $\begin{array}{l}T_{m}\left({ }^{\circ} \mathbf{C}\right) \\
140.5\end{array}$ & $\begin{array}{l}\text { \% Crystallinity } \\
6.72\end{array}$ & $\begin{array}{l}\sigma_{\max }(\mathbf{M P a}) \\
59 \pm 2\end{array}$ & $\begin{array}{l}E \text { (GPa) } \\
1.8 \pm 0.1\end{array}$ \\
\hline & $T_{\text {Liquefier }}=210^{\circ} \mathrm{C}$ & 62.2 & 109.7 & 146.9 & 5.12 & $60 \pm 1.5$ & $1.2 \pm 0.1$ \\
\hline & $T_{\text {Liquefier }}=220^{\circ} \mathrm{C}$ & 62 & 108.4 & 146.3 & 7.25 & $62 \pm 2$ & $1.4 \pm 0.1$ \\
\hline & $T_{\text {Liquefier }}=230^{\circ} \mathrm{C}$ & 62 & 107.8 & 146.4 & 6.83 & $57 \pm 1.5$ & $1.1 \pm 0.1$ \\
\hline
\end{tabular}

Abbreviations: DMA, dynamic mechanical analysis; DSC, differential scanning calorimetry. 
possibilities of polymer chain arrangements and (b) crystallization degree is higher for support temperature of $T=70^{\circ} \mathrm{C}$.

Following the tensile behavior and especially the failure strain (Figure 6), the increase of support temperature concluded in higher crystallinity and more ductility in the fabricated sample.
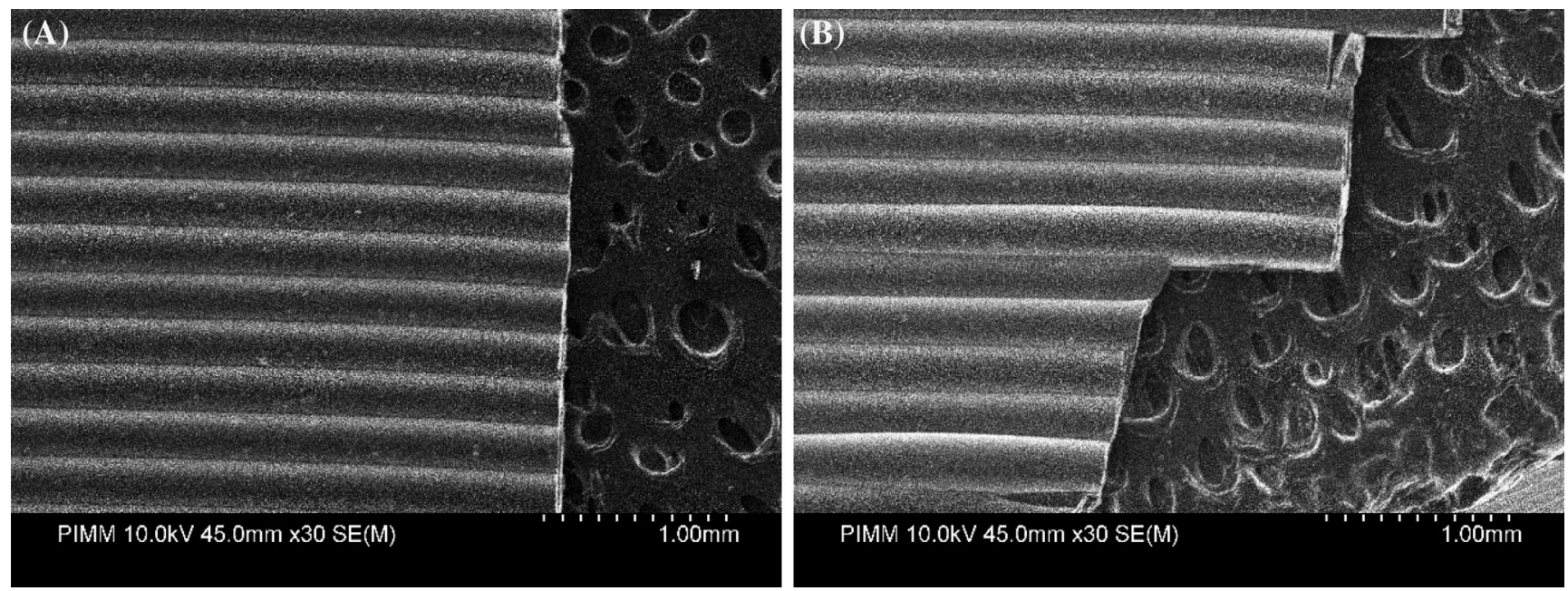

F I G U RE 4 Scanning electron microscope (SEM) micrographs for, A, and, B, at various location of failure sections for the fabricated sample at $T_{\text {liq }}=200^{\circ} \mathrm{C}$
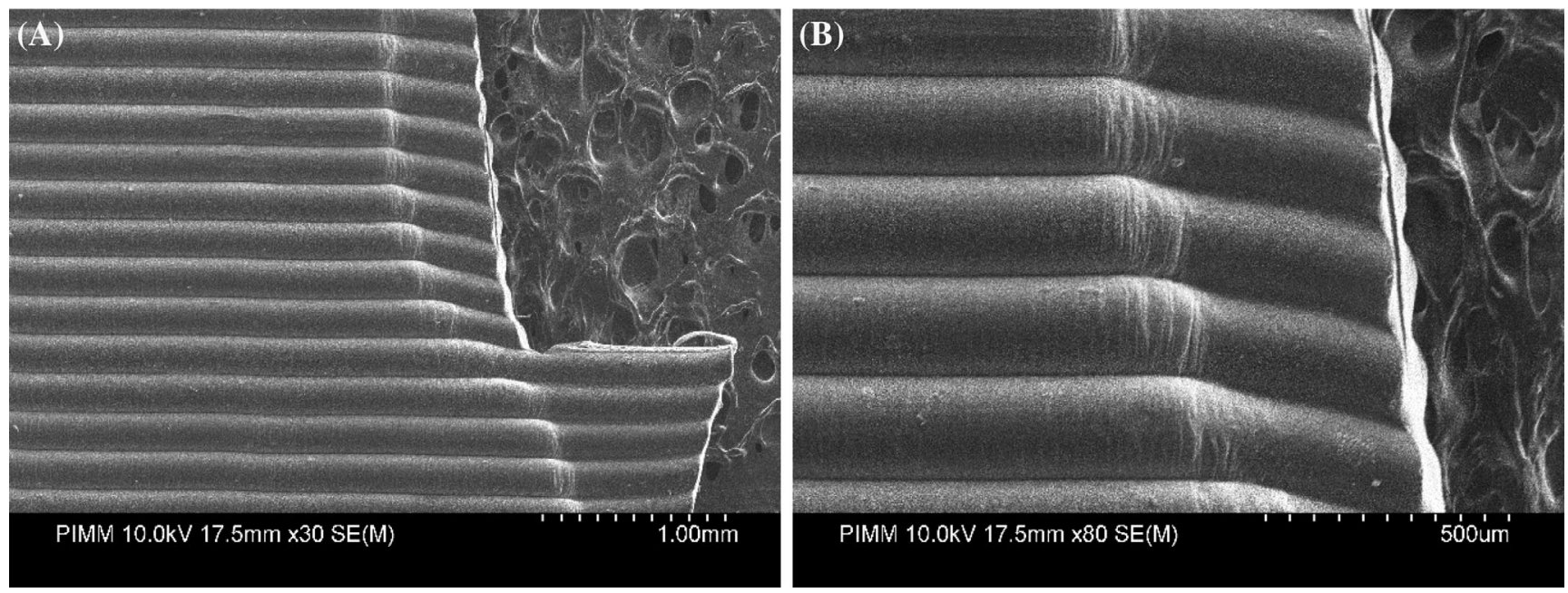

F I G U RE 5 Scanning electron microscope (SEM) micrographs for, A-D, at various location of failure sections for the fabricated sample at $T_{\text {liq }}=220^{\circ} \mathrm{C}$

T A B L E 4 Value of different properties obtained from DSC, DMA, and tensile results for condition No. 2

\begin{tabular}{llllllrr} 
Conditions & & $\boldsymbol{T}_{\boldsymbol{g}}\left({ }^{\circ} \mathbf{C}\right)$ & $\boldsymbol{T}_{\boldsymbol{c}}\left({ }^{\circ} \mathbf{C}\right)$ & $\boldsymbol{T}_{\boldsymbol{m}}\left({ }^{\circ} \mathbf{C}\right)$ & $\boldsymbol{\%}_{\text {Crystallinity }}$ & $\boldsymbol{\sigma}_{\max }(\mathbf{M P a})$ & $\boldsymbol{E}(\mathbf{G P a})$ \\
No. 2 & $T_{\text {Support }}=50^{\circ} \mathrm{C}$ & 62.2 & 109.7 & 146.9 & 5.12 & $60 \pm 1.5$ \\
& $T_{\text {Support }}=70^{\circ} \mathrm{C}$ & 62 & 107.8 & 146.4 & 6.83 & $61.5 \pm 2$ \\
\hline
\end{tabular}

Abbreviations: DMA, dynamic mechanical analysis; DSC, differential scanning calorimetry. 
However, the results of the tensile test performed for this condition demonstrated that the higher value of crystallinity degree causes higher ductility of the fabricated part. The results showed a similar Young's modulus value for different values of print speed.

\subsection{4 | Influence of layer height}

The last condition that has been considered is the influence of layer height on formation of adjacent filaments. Degree of crystallinity for each sample has been calculated. Results show that by increasing the layer height, degree of crystallinity is enhanced. Higher thickness can allow the gradient of temperature in each filament and consequent rearrangement of polymer chains (Table 6).

Tensile results present a higher ductility in layer height of $h=0.3 \mathrm{~mm}$, while Young's modulus values are the same.

Physicochemical and mechanical characterizations of fabricated parts in various processing conditions are

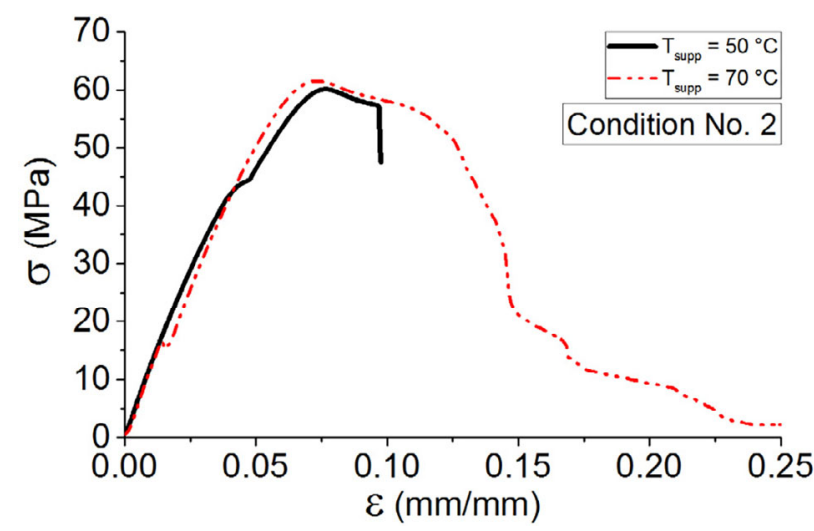

F I G URE 6 Tensile behavior of condition No. 2 for various support temperatures [Color figure can be viewed at wileyonlinelibrary.com] performed so far. The results comparison demonstrates that almost in each group of conditions, there might be a best value for a process parameter. However, it is difficult at this stage to have a conclusion related to the optimal values and process configuration. Hereafter, temperature profile of the vertical wall will be discussed.

\section{2 | Temperature profile of vertical wall}

Several experimental tests have been performed using local measurements in order to record the temperature profile of filaments in different locations. The recorded temperature profile is indicated for the first filament in a sequence of deposition at the location of $x=5 \mathrm{~mm}$ from the start of deposition (Figure 7). The aim is to recognize the temperature profile of adjacent filaments during deposition using in situ localized measurement.

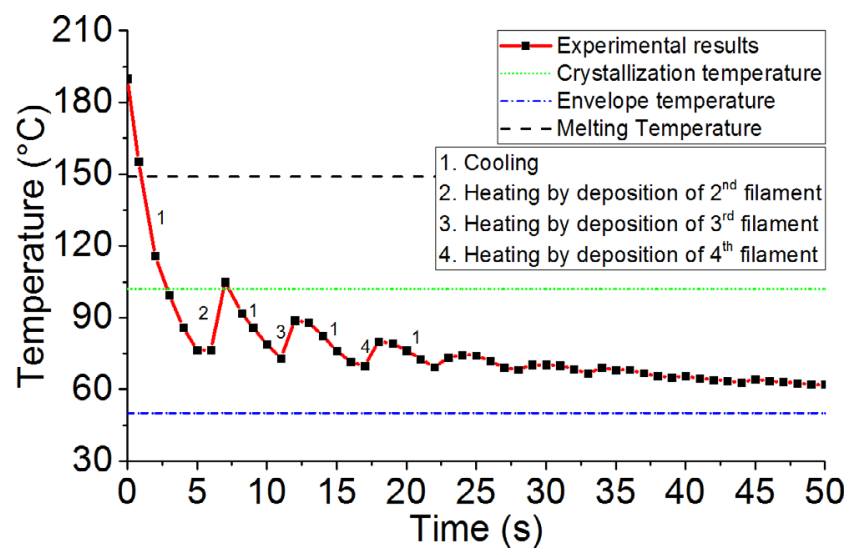

F I G U RE 7 Temperature evolution during fused filament fabrication process $\left(T_{\text {liq }}=210^{\circ} \mathrm{C}, T_{\text {supp }}=50^{\circ} \mathrm{C}, V=20 \mathrm{~mm} / \mathrm{s}\right.$, and $h=0.2 \mathrm{~mm}$ ) [Color figure can be viewed at wileyonlinelibrary.com]

TA B LE 5 Value of different properties obtained from DSC, DMA, and tensile results for condition No. 3

\begin{tabular}{llllllcr} 
Conditions & & $\boldsymbol{T}_{\boldsymbol{g}}\left({ }^{\circ} \mathbf{C}\right)$ & $\boldsymbol{T}_{\boldsymbol{c}}\left({ }^{\circ} \mathbf{C}\right)$ & $\boldsymbol{T}_{\boldsymbol{m}}\left({ }^{\circ} \mathbf{C}\right)$ & \% Crystallinity & $\boldsymbol{\sigma}_{\max }(\mathbf{M P a})$ & $\boldsymbol{E}(\mathbf{G P a})$ \\
No. 3 & $V=20 \mathrm{~mm} / \mathrm{s}$ & 62.2 & 109.7 & 146.9 & 5.12 & $60 \pm 1.5$ & $1.2 \pm 0.1$ \\
& $V=40 \mathrm{~mm} / \mathrm{s}$ & 62 & 108.4 & 146.3 & 6.83 & $56.5 \pm 2$ & $1.1 \pm 0.1$ \\
& $V=60 \mathrm{~mm} / \mathrm{s}$ & 62 & 107.8 & 146.4 & 7.25 & $56.5 \pm 2$ & $1 \pm 0.1$ \\
\hline
\end{tabular}

Abbreviations: DMA, dynamic mechanical analysis; DSC, differential scanning calorimetry.

T A B LE 6 Value of different properties obtained from DSC, DMA, and tensile results for condition No. 4

\begin{tabular}{llllllrr} 
Conditions & & $\boldsymbol{T}_{\boldsymbol{g}}\left({ }^{\circ} \mathbf{C}\right)$ & $\boldsymbol{T}_{\boldsymbol{c}}\left({ }^{\circ} \mathbf{C}\right)$ & $\boldsymbol{T}_{\boldsymbol{m}}\left({ }^{\circ} \mathbf{C}\right)$ & \multicolumn{1}{c}{ Crystallinity } & $\boldsymbol{\sigma}_{\mathbf{m a x}}(\mathbf{M P a})$ & $\boldsymbol{E}(\mathbf{G P a})$ \\
No. 4 & $h=0.1 \mathrm{~mm}$ & 62.3 & 108.4 & 140.5 & 6.72 & $56 \pm 2$ & $1.2 \pm 0.1$ \\
& $h=0.3 \mathrm{~mm}$ & 62 & 107.8 & 146.4 & 6.83 & $61.5 \pm 2$ & $1.3 \pm 0.1$ \\
\hline
\end{tabular}

Abbreviations: DMA, dynamic mechanical analysis; DSC, differential scanning calorimetry. 
As a case study (Figure 8), the evolution of temperature for filaments during deposition has been performed at various printing speeds (condition No. 3).

Results show that by increasing the printing speed, the temperature evolution of first deposited filament (at $x=5 \mathrm{~mm}$ from the deposition) remains above the crystallization temperature. This fact especially occurred at a printing speed of $V=60 \mathrm{~mm} / \mathrm{s}$. Based on the discussed results, increasing the print speed affects the degree of crystallinity and rearrangement of polymer chains by decreasing the cooling time. This is a preliminary result for measurement of the evolution of temperature during deposition and it is required to be studied numerically.

\section{5 | MICROSTRUCTURE ANALYSIS OF THE FABRICATED PARTS}

Figure 9 shows the microstructure analysis of the printed part (10 deposited filaments) for this condition: $T_{\text {liq }}=$ $210^{\circ} \mathrm{C}, T_{\text {supp }}=50^{\circ} \mathrm{C}, V=20 \mathrm{~mm} / \mathrm{s}$, and $h=0.2 \mathrm{~mm}$. The

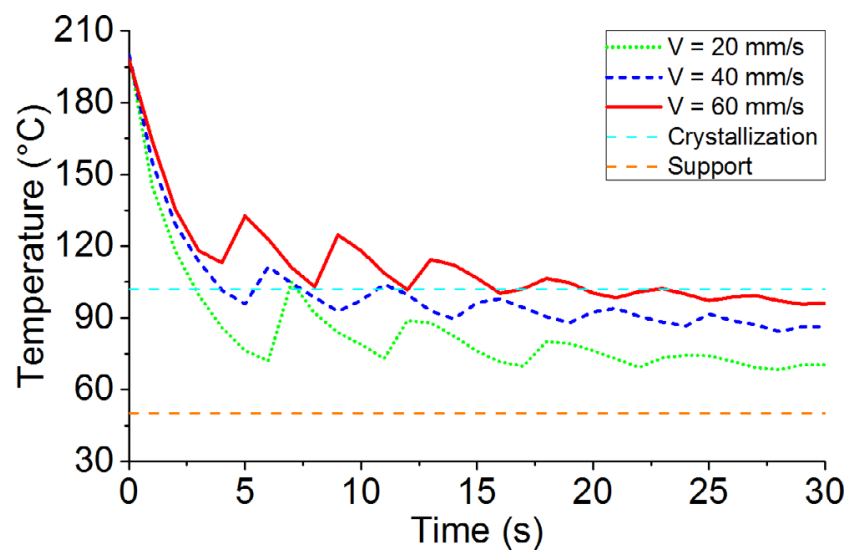

FI G U RE 8 Temperature evolution during fused filament fabrication process: effect of print speed [Color figure can be viewed at wileyonlinelibrary.com] aim is to show the contact surface of two adjacent filaments. Results show that as much as the distance from support increases, the contact surface of two adjacent filaments decreases. Also based on the temperature evolution of filaments (see Figure 7), one can observe that after two or three sequences of deposition, the temperature decreases below crystallization temperature. This fact contributes to the speed of cooling, solidification of material, lower material diffusion, and then decrease in the contact surface between two adjacent filaments.

This analysis performed on the samples by applying the process parameters. Figures 10 and 11 show the microstructure analysis of condition No. $1\left(T_{\text {liq }}=230^{\circ} \mathrm{C}\right)$ and condition No. $2\left(T_{\text {supp }}=70^{\circ} \mathrm{C}\right)$.

Each condition has its influence on the quality and microstructure of the fabricated parts. One can note that in condition No. $2\left(T_{\text {supp }}=70^{\circ} \mathrm{C}\right)$ after almost 10 deposited layers, perhaps due to high temperature, layers slide on each other as well as for condition No. $4(h=0.3 \mathrm{~mm})$. However, in condition No. $1\left(T_{\text {liq }}=230^{\circ} \mathrm{C}\right)$ after 20 deposited layers, filaments remain in a good quality of printing as well as condition No. $3(V=60 \mathrm{~mm} / \mathrm{s})$.

Based on the SEM observations, the same analysis performed on the deposit layers (Figure 12) and the percentages of the contact surface of each two adjacent filaments have been compared. This analysis is a useful summary of the effect of each process parameter. One can note that the influence of increasing the extruder temperature is more significant in comparison with other process parameters. As seen, the higher extruder temperature causes a higher contact surface between two adjacent filaments. However, the influence of print speed is more discussable based on the SEM micrograph performed on the sequence of layers. One can notice that the value of contact length between adjacent filaments is almost constant with increasing the printing speed. Moreover, the quality of the printed part is better.
FI G U RE 9 Analysis of the length of contact between two adjacent filaments.

$\left(T_{\text {liq }}=210^{\circ} \mathrm{C}, T_{\text {supp }}=50^{\circ} \mathrm{C}\right.$, $V=20 \mathrm{~mm} / \mathrm{s}$, and $h=0.2 \mathrm{~mm}$ ) [Color figure can be viewed at wileyonlinelibrary.com]
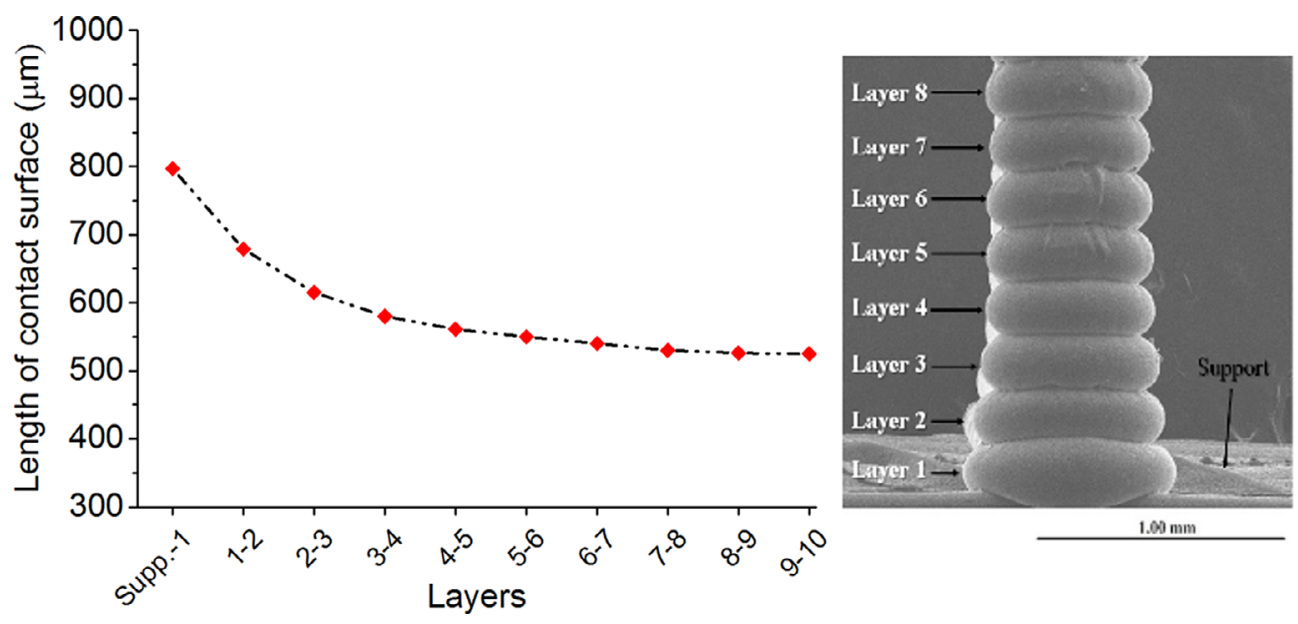

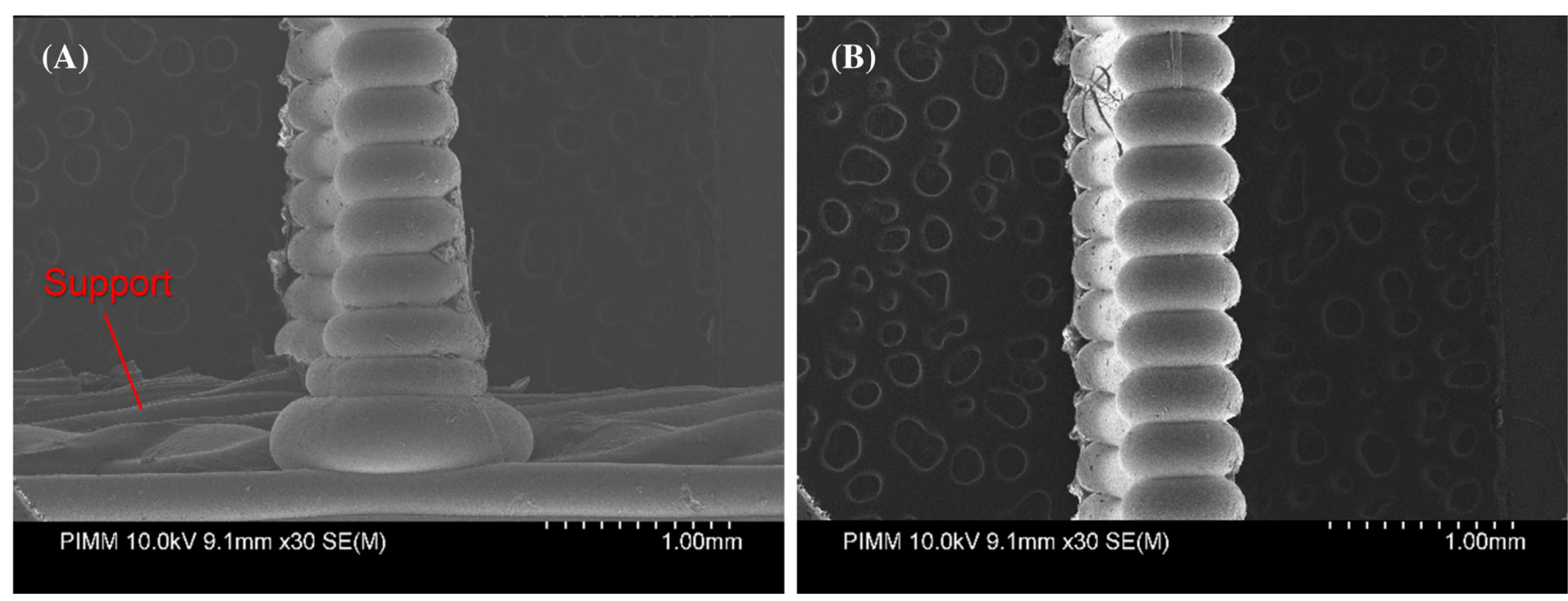

F I G U R E 10 Consequence of deposited filaments in condition No. $1\left(T_{\text {liq }}=230^{\circ} \mathrm{C}\right)$ for, A, layers 1 to 8 and, B, layers 9 to 17 [Color figure can be viewed at wileyonlinelibrary.com]
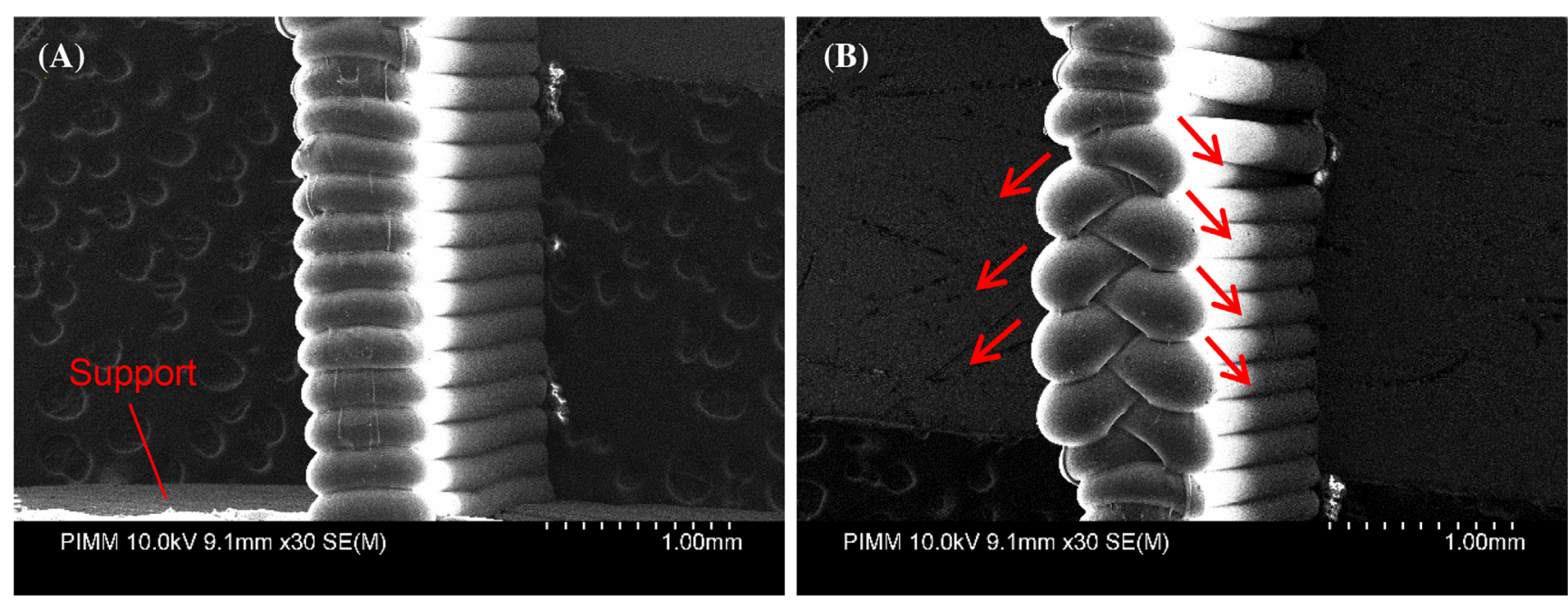

F I G U RE 11 Consequence of deposited filaments in condition No. $2\left(T_{\text {supp }}=70^{\circ} \mathrm{C}\right)$ for, A, layers 1 to 12 and, B, layers 13 to 26 [Color figure can be viewed at wileyonlinelibrary.com]

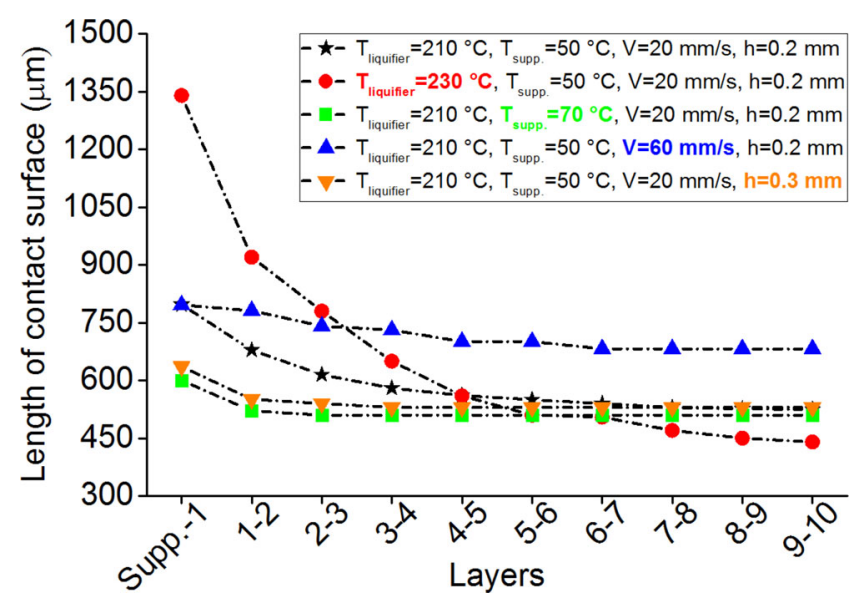

F I G U RE 12 Analysis of the length of contact between two adjacent filaments [Color figure can be viewed at wileyonlinelibrary.com]

\section{6 | CONCLUSIONS}

This work presents an experimental investigation on the influence of process parameters on thermal and mechanical properties of PLA in FFF process. The preliminary physicochemical and mechanical results showed that there is a difference in the degree of crystallinity during the cooling process and formation of adjacent filaments. Young's modulus and failure strain could be an indicator to evaluate the mechanical properties of FFF fabricated parts. However, the temperature profile measurement of filaments indicates that process parameters have a significant impact on the mechanical strength of the fabricated parts. The results showed that, although it is required to consider the interaction of parameters, the evaluation of each could help to study the strength in FFF process. 
One can notice that the effect of different parameters should be investigated at multiscale analysis. The latter can confirm that perhaps we have good mechanical properties of fabricated parts; however, the microstructure of the pieces is not acceptable. Presumably, the influence of increasing the extruder temperature is more significant in comparison with other process parameters: the higher the extruder temperature, the higher the contact surface between two adjacent filaments. However, the influence of print speed is more discussable based on the SEM micrograph performed on the sequence of layers.

\section{CONFLICT OF INTEREST}

The authors declare no potential conflicts of interest.

\section{ORCID}

Hamidreza Vanaei (D) https://orcid.org/0000-0003-1501-

0482

\section{REFERENCES}

[1] S.-S. Yao, F.-L. Jin, K. Y. Rhee, D. Hui, S.-J. Park, Compos. Part B: Eng. 2018, 142, 241.

[2] P. Chennakesava, Y. S. Narayan, "Fused deposition modelinginsights," In Proc. of the Int. Conf. on Advances in Design and Manufacturing ICAD\&M. 2014; Vol. 14, pp. 1345-1350.

[3] Q. Sun, G. Rizvi, C. Bellehumeur, P. Gu, Rapid Prototyp. J. 2008, 14(2), 72 .

[4] C. Bellehumeur, M. Bisaria, J. Vlachopoulos, Polym. Eng. Sci. 1996, 36(17), 2198.

[5] H. S. Patanwala, D. Hong, S. R. Vora, B. Bognet, A. W. Ma, Polym. Compos. 2018, 39(S2), E1060.

[6] D. Depuydt, M. Balthazar, K. Hendrickx, W. Six, E. Ferraris, F. Desplentere, J. Ivens, A. W. van Vuure, Polym. Compos. 2019, 40(5), 1951.

[7] F. Arbeiter, M. Spoerk, J. Wiener, A. Gosch, G. Pinter, Polym. Test. 2018, 66, 105.

[8] J. Chacón, M. A. Caminero, E. García-Plaza, P. J. Núñez, Mater. Des. 2017, 124, 143.

[9] M. Á. Caminero, J. M. Chacón, E. García-Plaza, P. J. Núñez, J. M. Reverte, J. P. Becar, Polymers 2019, 11(5), 799.

[10] S. Costa, F. Duarte, J. A. Covas, Using MATLAB to compute heat transfer in free form extrusion. in MATLAB-A Ubiquitous Tool for the Practical Engineer (Ed: C. M. Ionescu), InTech, Rijeka, Croatia 2011, p. 453.

[11] A. Bellini, Ph.D Thesis, Drexel University (Philadelphia, PA) 2002.

[12] L. Li, Q. Sun, C. Bellehumeur, P. Gu, "Investigation of Bond Formation in FDM Process 400," In 2002 Int. Solid Freeform Fabrication Symp. 2002.

[13] O. Pokluda, C. T. Bellehumeur, J. Vlachopoulos, AIChE J. 1997, 43(12), 3253.

[14] O. A. Mohamed, S. H. Masood, J. L. Bhowmik, Mater. Today: Proc. 2017, 4(8), 8250.
[15] M. A. Cuiffo, J. Snyder, A. M. Elliott, N. Romero, S. Kannan, G. P. Halada, Appl. Sci. 2017, 7(6), 579.

[16] W. Wu, P. Geng, G. Li, D. Zhao, H. Zhang, J. Zhao, Materials 2015, 8(9), 5834.

[17] B. Huang, S. Meng, H. He, Y. Jia, Y. Xu, H. Huang, Polym. Eng. Sci. 2019, 59(1), 120.

[18] M. Harris, J. Potgieter, R. Archer, K. M. Arif, Mater. Manuf. Process. 2019, 34(6), 701.

[19] J. Torres, J. Cotelo, J. Karl, A. P. Gordon, JOM 2015, 67(5), 1183.

[20] F. Górski, W. Kuczko, R. Wichniarek, Arch. Mech. Technol. Autom. 2014, 31(1), 3.

[21] F. Górski, R. Wichniarek, W. Kuczko, J. Andrzejewski, J. Mach. Eng. 2015, 15(4), 121.

[22] T. Letcher, B. Rankouhi, S. Javadpour, "Experimental study of mechanical properties of additively manufactured ABS plastic as a function of layer parameters," In ASME 2015 Int. Mechanical Engineering Congress and Exposition, American Society of Mechanical Engineers Digital Collection, New York, NY. 2015.

[23] O. Es-Said, J. Foyos, R. Noorani, M. Mendelson, R. Marloth, B. Pregger, Mater. Manuf. Process. 2000, 15(1), 107.

[24] S. H. Ahn, M. Montero, D. Odell, S. Roundy, P. K. Wright, Rapid Prototyp. J. 2002, 8, 248.

[25] H. Li, T. Wang, J. Sun, Z. Yu, Rapid Prototyp. J. 2018, 24, 80.

[26] X. Liu, M. Zhang, S. Li, L. Si, J. Peng, Y. Hu, Int. J. Adv. Manuf. Technol. 2017, 89(5-8), 2387.

[27] S. Xiaoyong, C. Liangcheng, M. Honglin, G. Peng, B. Zhanwei, L. Cheng, "Experimental analysis of high temperature PEEK materials on 3D printing test," In 2017 9th Int. Conf. on Measuring Technology and Mechatronics Automation (ICMTMA). IEEE. 2017, pp. 13-16.

[28] A. K. Sood, R. K. Ohdar, S. S. Mahapatra, Mater. Des. 2010, 31 (1), 287.

[29] R. Zaldivar, D. Witkin, T. McLouth, D. Patel, K. Schmitt, J. Nokes, Addit. Manuf. 2017, 13, 71.

[30] J. F. Rodríguez, J. P. Thomas, J. E. Renaud, Rapid Prototyp. J. 2001, 7, 148.

[31] R. Vadori, A. K. Mohanty, M. Misra, Macromol. Mater. Eng. 2013, 298(9), 981.

[32] A. Kallel, I. Koutiri, E. Babaeitorkamani, A. Khavandi, M. Tamizifar, M. Shirinbayan, A. Tcharkhtchi, Int. Polym. Process. 2019, 34(4), 434

[33] A. Lucas, A. Danlos, M. Shirinbayan, V. Motaharinejad, R. Paridaens, K. Benfriha, F. Bakir, A. Tcharkhtchi, Int. J. Adv. Manuf. Technol. 2019, 104(1-4), 1183. 